\title{
Effect of Yogic Exercise on Selected Pulmonary Function Tests in Apparently Healthy Elderly Subjects
}

\author{
Tamal Chakraborty ${ }^{1}$, Kakali Das (Sarkar) ${ }^{2}$, Kaushik Samajdar ${ }^{3}$ \\ ${ }^{I}$ Department of Physiology, North Bengal Medical College, India \\ ${ }^{2}$ Department of Physiology, N.R.S. Medical College, India \\ ${ }^{3}$ Department of Physiology, North Bengal Medical College, India
}

\begin{abstract}
A case control study was done to find out the effects of simple yogic exercise programs (asanas and pranayamas) on selected pulmonary function tests of forty elderly individuals of both sexes, between 50 and 70 years of age, with no active medical disorders. The study was conducted at a selected yoga centre in Siliguri town of Darjeeling district of West Bengal. Forced Vital Capacity (FVC), Forced Expiratory Volume in one second $\left(F E V_{l}\right)$ and Peak Expiratory Flow Rate (PEFR) were measured, once initially and again after six weeks of yoga training under supervision of a certified yoga instructor. Two instruments were used: a) A Vitalograpgh Gold Standard Spirometer; b) A Wright's Peak Flow meter. There was definite improvement of ventilatory functions as revealed by significant increase in FVC, FEV $V_{I}$ and PEFR that was measured after 6 weeks. $(P<0.05)$
\end{abstract}

Keywords: Forced Expiratory Volume in one second (FEV $\left.{ }_{l}\right)$, Forced Vital Capacity (FVC), Peak expiratory flow rate (PEFR), yogic exercises, elderly people.

\section{Introduction}

Yoga is practised in India over thousands of years. It aims at perfection of body and mind [1], produces consistent physiological changes and has scientific basis. It is said to help in increasing longevity and to have a therapeutic and rehabilitative effect. The efficiency of respiratory system and ventilation declines as age advances due to various factors. Pranayama, the well known yogic practice, has beneficial effects on respiratory efficiency. These exercises help to empty and fill the respiratory apparatus more completely and efficiently, leading to increased development of respiratory musculature, as is recorded in terms of Forced Vital Capacity (FVC). Similar ventilatory training, even in elderly subjects (between 60 and 75 years), has been shown to improve lung volumes and capacities [2]. A study performed on a group of elderly people (aged 41 to 50 years) indicated that, a short term yoga practice (posture and pranayama) was beneficial and prevented development of primary respiratory problems by increasing the efficacy of respiratory muscles [3]. Joshi et al reported significant increase in FVC and Peak Expiratory Flow Rate (PEFR) following 6 weeks of Pranayama practice [4]. Makwana et al reported significant increase in FVC \& Forced Expiratory Volume in one minute $\left(\mathrm{FEV}_{1}\right)$ following 10 weeks of yoga training [5]. Vital capacity was measured before and after 17 weeks of regular practice of yoga postures and breathing exercises in a large group of college students in the USA, and the study showed statistically significant increase in vital capacity across all categories over time [6]. Bijlani and others have also reported similar observations [7]. Our study was aimed to find out the effect of yoga on selected pulmonary function tests on healthy elderly people of Siliguri, a sub-Himalayan town in northern part of West Bengal.

\section{Subjects}

\section{Materials and methods}

The study was conducted at a selected yoga centre in Siliguri town of Darjeeling district of West Bengal, India. Forty subjects, including both male and female, of age group of 50 to 70 years, with no respiratory, cardiovascular or other medical disorders, were selected for the study.

\section{Exclusion criteria:}

a) History of active sports training

b) Previous experience of yoga training

c) History of active medical illness e.g. tuberculosis, chronic lung disease, symptomatic ischemic heart disease.

d) History of major surgery in recent past

e) Smoker

f) Intake of regular medicines for hypertension or diabetes mellitus

g) Any vertebral deformities e.g. kyphosis or scoliosis

Each subject was separately explained about the study procedure and his / her consent was obtained. They were then taught different yogic exercises by a certified yoga instructor and advised to practise specifically those 
exercises in 30 minutes' session regularly for 6 (six) weeks under supervision.

Approval from the institutional ethics committee was obtained.

Before the actual yogic exercise training programme commenced, measurement of the following parameters was done in each subject:

a) Forced Vital Capacity (FVC): After the patient has taken in the deepest possible breath, this is the volume of air which can be forcibly and maximally exhaled out of the lungs until no more can be expired. FVC is usually expressed in litres.

b) Forced Expiratory Volume in One Second $\left(\mathrm{FEV}_{1}\right)$ : This is the volume of air which can be forcibly exhaled from the lungs in the first second of a forced expiratory manoeuvre. It is expressed in litres. FVC \& FEV 1 values are critically important in the diagnosis of obstructive and restrictive diseases.

c) Peak Expiratory Flow Rate (PEFR): It is a simple test for the efficacy of respiratory system. It is the largest expiratory flow rate achieved with a maximally forced effort from a position of maximal inspiration, expressed in litres per minute (American Thoracic Society). PEFR was introduced by Hadorn in 1942, and was accepted in 1949 as an index of spirometry [8].

\section{Instruments used}

a) Vitalograph (Gold Standard Spirometer): [9] It is a lightweight, compact and a permanent calibrated instrument that provides a permanent volume / time tracing of lung functions by recording a dynamic and static tracing of expiration of lung volume (FVC \& FEV $\left.{ }_{1}\right)$.

b) Wright's Peak Flow Meter: [10] It is a hand-held device into which the patient blows with maximum force after a deep breath and which shows the peak flow rate reached during the forced expiration.

In both cases, 3 readings were taken at intervals of one minute, and the maximum values were selected for the report.

The yogic exercises allotted to the participants were as follows: [11]

1. Bhastika Pranayama

Procedure: To take in deep breaths and then completely breathe out.

Duration: 3 minutes.

\section{Kapal Bhati Pranayama}

Procedure: To push air forcefully out through the nostrils and the anterior abdominal wall itself goes in rhythmically with each expiratory movement. The subject then inhales immediately and quickly and repeats the procedure.

Duration: to start for one minute, and gradually increase to 5 minutes.

\section{Bahya Pranayama}

Procedure: To breathe air out, touch the chin to the chest, squeeze stomach completely and hold for a while; then release the chin, breathe in slowly.

Duration: 5 times for one minute of each session.

\section{Anulom Vilom Pranayama}

Procedure: To hold the right nostril with thumb, breathe in from left nostril. Now open the right nostril and close the left one with the middle and ring fingers, and breathe out from the right nostril. Now breathe in from the right nostril. Then close the right nostril and open the left one and breathe out from it, and continue as above.

Duration: at least 10 minutes.

After completion of the exercise programme at the end of 6 weeks, the subjects were asked to present themselves at the yogic centre for reassessment of their respiratory parameters, namely, FVC, FEV ${ }_{1} \& \mathrm{PEFR}$

After the tests were done, data was compiled and put for analysis.

\section{Results}

The statistical method applied for analysis of the data from the study was Paired Samples ' $t$ ' test. This procedure compares the 'mean' of two variables for a single group. $\mathrm{P}<0.05$ was considered significant. This was a prospective study. Forty subjects $(n=40)$ of both sexes of age between 50 and 70 years were chosen for the study. Each subject was separately explained about the study procedure and consent was obtained from them. The following parameters were measured in each subject twice during the study - once at the onset of the study, i.e. before starting of yoga practice; and once after the completion of six weeks of yoga training and practice under supervision:

a) Forced Vital Capacity (FVC) expressed as litre

b) Forced expiratory volume in first second $\left(\mathrm{FEV}_{1}\right)$ expressed as litre

c) Peak expiratory flow rate (PEFR) expressed as litre/minute.

Results showed that there was a significant increase in FEV 1, FVC and PEFR. 
Tables I, II and III show the comparison of the results of the three parameters measured. Table IV shows the comparative study of all the parameters measured before and after the exercise training. The tables are given at the end.

\section{Discussion}

Forty subjects of both sexes of age group 50 to 70 years with no active respiratory, cardiovascular and other medical illness were selected for the study. After taking pre-exercise recordings of FVC, FEV 1 and PEFR, subjects were made to undergo a 6 weeks' yogic exercise training programme and then recordings of the same parameters were obtained at the end of the programme. Data analysis revealed that, there was a significant increase in all the three parameters. The Tables I, II and III show the comparison of results of FEV ${ }_{1}$, FVC and PEFR respectively performed before and after exercise training. Table IV shows the comparative study of all the parameters, performed once before and then after yogic training for 6 weeks. The changes were significant in all the cases. The efficiency of respiratory system and ventilation declines as age advances [1]. This is a general observation and it may be due to decreased elasticity of the lung tissue and reduced muscular power and stiffness of the thoracic cage. A reduced mechanical efficiency decreases alveolar ventilation. In effect the oxygenation of the tissues will be less than that seen in the young healthy individuals. The loss of elastic recoiling prevents the closure of respiratory bronchioles during expiration. And further to this, the rate of deterioration of PEFR is more in the following decades. Thereafter the capacity of respiratory system becomes very low in the old age above 70 years. A compromised respiratory efficiency reduces the individual's stress tolerance which affects the quality of life. Pranayama, a yogic practice, has beneficial effects on respiratory efficiency. It includes various exercises which involve forceful inspiration to total lung capacity (TLC) and forceful exhalation to residual volume, and all manoeuvres are done through nostrils, which offer resistance by means of decreased cross sectional area and turbulence. Breathing through one nostril in Anulom-vilom pranayama further increases the resistance. Higher peak expiratory flow rates and $\mathrm{FEV}_{1}$ could be explained due to better strengthening of respiratory muscles in yogis. By yoga practice respiratory apparatus is emptied and filled more completely and efficiently which is recorded in terms of increased forced vital capacity (FVC) [6, 12]. Yogic breathing creates more negative pressures in both abdominal and thoracic cavity during inspiration and moves the diaphragm more than its normal excursions and helps in efficient movement of diaphragm, intercostals and abdominal muscles. Thus the improvement in vital capacity is due in part to increased development of respiratory musculature incidental to regular practice of yogic exercise [13].

Skeletal muscles control many crucial elements of aerobic conditioning including lung ventilation. Repeated inspirations to TLC and breath holdings as done during pranayama can lead to increase in the maximal shortening of the inspiratory muscles which has been shown to improve the lung function parameters [14]. Yoga postures involve isometric contraction which is known to increase skeletal muscle strength [15]. In addition to improved respiratory muscle performance, increased $\mathrm{FEV}_{1}$ in yogic practitioners may be because of improved patency of airways $[4,7]$. Yoga with its calming effect on the mind can reduce and release emotional stresses, hereby withdrawing the bronchoconstrictor effect $[12,16,17]$. Lung inflation near to total lung capacity is a major physiological stimulus for the release of lung surfactant and prostaglandins into alveolar space, which increases lung compliance and decreases bronchiolar smooth muscle tone, respectively [4, 14, 17]. Thus, the respiratory efficacy greatly improves after exercise even in the elderly, which go a long way in healthy living. Hence elderly people must be trained in systematic physical activity under suitable guidance to improve their quality of life [18]. It has also been reported that regular practice of yogic exercises in sedentary subjects was almost equivalent to swimming in improving their pulmonary functions when practised for 12 weeks [19].

In light of these facts, yogic exercise can become the most important way of lifestyle intervention and physical activity for prevention of many diseases as prescribed by World Health Organization [20], especially in the elderly, where rigorous physical exercise is not always advisable.

\section{Conclusion}

The conclusion observed in our scientific study was as follows. Six weeks of regular yogic training in elderly individuals aged between 50 to 70 years showed definite improvement in their ventilatory functions, as observed from improvement in their FVC, $\mathrm{FEV}_{1}$ and PEFR. This may be due to regular slow and forceful inspiration and expiration during yoga practice, leading to strengthening of respiratory muscles; and increased release of surfactant too. Further study is needed to find out other causes.

\section{Acknowledgements}

We wish to thank our extremely cooperative subjects; the Head of the Institution, NBMC; and Professor A.K. Mukhopadhyay, Head of the Department of Physiology, N.R.S. Medical College, for his constant guidance and encouragement. 
Effect Of Yogic Exercise On Selected Pulmonary Function Tests In Apparently Healthy Elderly Subjects

Table I: COMPARISON OF FEV 1 (L/sec) READINGS BEFORE \& AFTER YOGIC EXERCISE

\begin{tabular}{|c|c|c|c|c|c|c|}
\hline & $\begin{array}{c}\text { Smallest } \\
\text { Observation }\end{array}$ & $\begin{array}{c}1^{\text {st }} \text { quartile } \\
(\mathrm{Q} 1)\end{array}$ & $\begin{array}{c}\text { Median } \\
(\mathrm{Q} 2)\end{array}$ & $\begin{array}{c}3^{\text {rd }} \text { quartile } \\
(\mathrm{Q} 3)\end{array}$ & IQR & $\begin{array}{c}\text { Largest } \\
\text { Observation }\end{array}$ \\
\hline Before Yoga & 1.03 & 1.328 & 1.76 & 1.895 & 0.5675 & 2.17 \\
\hline After Yoga & 1.13 & 1.385 & 1.78 & 1.93 & 0.545 & 2.23 \\
\hline
\end{tabular}

There was definite improvement in $\mathrm{FEV}_{1}$ after 6 weeks of yoga training.

Table II:COMPARISON OF FVC (L) READINGS BEFORE \& AFTER YOGIC EXERCISE:

\begin{tabular}{|c|c|c|c|c|c|c|}
\hline & $\begin{array}{c}\text { Smallest } \\
\text { Observation }\end{array}$ & $\begin{array}{c}1^{\text {st }} \text { quartile } \\
(\mathrm{Q} 1)\end{array}$ & $\begin{array}{c}\text { Median } \\
(\mathrm{Q} 2)\end{array}$ & $\begin{array}{c}3^{\text {rd }} \text { quartile } \\
(\mathrm{Q} 3)\end{array}$ & IQR & $\begin{array}{c}\text { Largest } \\
\text { Observation }\end{array}$ \\
\hline Before Yoga & 1.32 & 1.8075 & 2.15 & 2.3125 & 0.505 & 2.49 \\
\hline After Yoga & 1.35 & 1.83 & 2.18 & 2.33 & 0.500 & 2.47 \\
\hline
\end{tabular}

FVC also showed remarkable improvement after 6 weeks of regular yoga practise under supervision.

Table III: COMPARISON OF PEFR (L/min) READINGS BEFORE \& AFTER YOGIC EXERCISE:

\begin{tabular}{|c|c|c|c|c|c|c|}
\hline & $\begin{array}{c}\text { Smallest } \\
\text { Observation }\end{array}$ & $\begin{array}{c}1^{\text {st }} \text { quartile } \\
(\mathrm{Q} 1)\end{array}$ & $\begin{array}{c}\text { Median } \\
(\mathrm{Q} 2)\end{array}$ & $\begin{array}{c}3^{\text {rd }} \text { quartile } \\
(\mathrm{Q} 3)\end{array}$ & IQR & $\begin{array}{c}\text { Largest } \\
\text { Observation }\end{array}$ \\
\hline Before Yoga & 300.77 & 312.46 & 346.45 & 354.25 & 41.79 & 389.67 \\
\hline After Yoga & 305.75 & 319.7025 & 347.38 & 363.605 & 43.90 & 395.37 \\
\hline
\end{tabular}

PEFR also showed remarkable change after 6 weeks of regular yogic exercises.

Table IV: COMPARASION OF READINGS OF THE PARAMETERS BEFORE AND AFTER YOGIC EXERCISE. (All values are mean $+/-\mathrm{SD}, \mathrm{n}=40$ in each group).

\begin{tabular}{|c|c|c|c|}
\hline & $\mathrm{FEV}_{\mathbf{1}}(\mathrm{L} / \mathrm{sec})$ & $\mathrm{FVC}(\mathrm{L})$ & PEFR (L/min) \\
\hline Before yoga & $1.6365 \pm 0.317$ & $2.0855 \pm 0.288$ & $339.0102 \pm 24.976$ \\
\hline After yoga & $1.6758 \pm 0.305$ & $2.1048 \pm 0.293$ & $343.3453 \pm 25.086$ \\
\hline Significance & $\mathrm{S}$ & $\mathrm{S}$ & $\mathrm{S}$ \\
\hline
\end{tabular}

$\mathrm{S}: \mathrm{P}<0.05$.

All the observations are highly significant. This study shows that there is significant improvement of $\mathrm{FEV}_{1}$, FVC and PEFR in all subjects after 6 weeks of regular yoga training.

\section{References:}

[1]. Bijlani RL. Physiological effects of yogic practices. In: Understanding Medical Physiology; $4^{\text {th }}$ Edition. Jaypee Brothers Medical Publishers, Ch 17.5, pg 765 .

[2]. Belman MJ, Gaesser GA. Ventilatory muscles training in the elderly. J Appl Physiol 1983; 64: 899-905.

[3]. Ahmed QR, Sau SK, Kar SK. An evaluation of pulmonary parameters in two groups of subjects during yoga practice. Nepal Med Coll J 2010; 12(3): 180-182.

[4]. Joshi LN, Joshi VD, Gokhale LV. Effect of short term "Pranayam" practice on breathing rate and ventilatory functions of lungs. Indian J Physiol Pharmacol 1992; 36: 105-108.

[5]. Leelver BH, Butter J. Alteration in pulmonary function: In Principles of geriatric medicine 1985; 26: $280-57$.

[6]. Birkel DA, Edgren L. Hatha Yoga: Improved vital capacity of college students. Altern Ther Health Med 2000; 6:55-63.

[7]. Nayar HS, Mathur RM, Kumar RS. Effects of yogic exercises on human physical efficiency. Indian J Med Res 1975; 63: 13691376.

[8]. Jain SK, Kumar R, Sharma DA. Factors influencing peak expiratory flow rate in normal subjects. Lung India 1983; 3:92-97.

[9]. User Manual: Vitalograph Gold Standard with 12 seconds chart. [Online]. 2004 [cited 2004 Aug 22]; Available from: URL: http://www.vitalograph.com/products/vitalograph gold standard.php

[10]. Peak Flow $\quad$ Measurement $\quad$ [Online]. $2011 \quad$ [cited $2011 \quad$ Sep 10$]$; Available from: URL:http://www.muschealth.com/gs/TandPcontent.aspx/pageid=P07755

[11]. Dhillon SS. A simple solution to America's weight problem: Banish belly and lose weight in just 5 minutes a day. New York: Amazon Publications, 2010, 148-149.

[12]. Yadav RK, Das S. Effect of yogic practice on pulmonary functions in young females, Indian J Physiol Pharmacol 2001; 45(4):493496.

[13]. Bhole MV. Treatment of bronchial asthma. Yoga Mimansa 1967; 9:33.

[14]. Mehrotra PK, Verma N, Tiwari S, Kumar P. Pulmonary functions in Indian sportsmen playing different games. Indian J Physiol Pharmacol 1998;42:412-6. 
[15]. Gopal KS, Bhatnagar OP, Subramanian N, Nishith SD. Effect of yogasanas and pranayamas on blood pressure, pulse rate and respiratory functions. Indian J Physiol Pharmacol 1973;17:273-6.

[16]. Makwana K, Khirwadkar B, Gupta HC. Effect of short term yoga practice on ventilatory function tests. Indian J Physiol Pharmacol 1988; 32: 202-208.

[17]. Srivastava RD, Jain N, Singhal A. Influence of alternate nostril breathing on cardiorespiratory and autonomic functions in young healthy adults. Indian J Physiol Pharmacol 2005;49:475-83.

[18]. Shyamala KV, Ganaraja B, Adhikari P, Ravichandra V, Ramesh Bhat M. Controlled exercise increases pulmonary efficacy in the elderly. Thai J Physiol Sciences 2008; 21(1):14-17.

[19]. Gupta SS, Sawane MV. A comparative study of the effects of yoga and swimming on pulmonary functions in sedentary subjects. International J of Yoga; 2012; 5(2): 128-133.

[20]. World Health Organization. Global recommendations on physical activity for health. World Health Organization; 2010, p. 57. 